\title{
THE ECOLOGICAL APPROACH TO THE VISUAL PERCEPTION OF PICTURES*
}

\author{
James J. Gibson**
}

Having rejected the picture theory of natural perception we can make a start on picture perception. To see the environment is to extract information from the ambient array of light. What is it, then, to see a picture of something? The information in ambient light does not consist of forms and colors but of invariants. Is it implied that the information in a picture does not consist of forms and colors but of invariants? That sounds very odd, for we suppose that a picture is entirely composed of forms and colors.

The kind of vision we get from pictures is harder to understand than the kind we get from ambient light, not easier. It should be considered at the end of a treatise on perception, not at the beginning. It cannot be omitted, for pictures are an essential part of human life as much as words. They are deeply puzzling and endlessly interesting. What are pictures and what do they do for us?

\section{THE SHOWING OF DRAWINGS}

For countless centuries, certainly since the cave men, the artist has been making a drawing, showing it to his neighbor and asking him what he saw. Some time around a century ago the psychologist thought of presenting a drawing to his observer under controlled conditions and finding out what he perceived with systematic variation of the drawing. This made the procedure an experiment with an independent variable and a dependent variable consisting of the verbal (or other) response. But actually the artist was experimenting with perception all along, as much as the psychologist, even if not formally.

This ancient procedure is easy to carry out but it is not a good way to begin the study of perception, for the observer is never quite sure how to answer the question 'what do you see'. A drawing does not have ecological validity. I use 'drawing' in a general sense which includes a scribble form, or pattern as well as a picture. It is the procedure that perceptionists use, however, on the assumption that a form on the retina is the basic stimulus and that form perception is the primary kind. A drawn form on paper is also said to be a stimulus, loosely speaking, and thus an experimenter can 'apply' it to an animal or a baby as well as an adult. But is this a good way to begin the study of perception?

My own first effort in psychology was an experiment on the perception of drawings [1], and I have been puzzling about such experiments ever since. My subjects had to reproduce the figures they were shown, but you can have them recognized, or matched, or described in words, or

*An abridged version of Chapter 14 in the forthcoming book entitled The Ecological Approach to Visual Perception to be published by Houghton Mifflin, Boston MA, U.S.A.

**Psychologist, Dept. of Psychology, Uris Hall, Cornell University, Ithaca, NY 14853, U.S.A. completed from a part You can present line-drawings or silhouettes, closed outlines or open, nonsense figures or meaningful ones, regular forms or irregular ones, simple or complex forms, scribbles or depictions, nameless blobs or specific representations, hen-tracks or alphabetic characters, cursive letters or printed letters, upright forms or inverted forms, 'good' forms or 'bad' forms. All these variations and many others have been tried out. The results are disappointing. After hundreds of experiments nothing decisive has emerged about visual perception, only perplexities. Wherein lies the meaning? Does a drawing have an intrinsic meaning or only an arbitrary meaning? Are there laws of organization that apply or only laws of association? Are there significant forms as such or only forms that represent objects? Can forms represent solid objects or only flat objects. If the former, how?

Meanwhile of course, modern artists of various schools have also been experimenting. Their drawings and paintings are said to be non-representative, or non-objective, or non-figurative, or sometimes abstract, but the question is what do we see? The artists have tried out a wider range of variations than the psychologists, not having to worry about explicitness, and a whole crowd of professional art critics has come to exist trying to make them explicit. They too, it seems to me, have not made any significant discoveries about visual perception. The old perplexities are unresolved.

The central fallacy of the picture theory of perception

The showing of drawings is thought to be a good way to begin the study of perception, because vision is supposed to be simplest when there is a form on the retina that is a copy of a form on a surface facing the retina. The retinal form is then in point-to-point correspondence with the drawn form, although inverted. But this is not the simplest case of vision. Visual awareness of the surroundings cannot be explained on this supposition. Not even visual awareness of an object in space can be explained by it since, for any given form, there exists an infinite set of possible objects in space and, for any given solid object that moves, there exists an infinite set of possible forms. A frozen form does not specify the solid shape of an object, only some of the invariant features that a solid object must have. And in any case we never see just a form but a sample of the ambient optic array. If I am right, most of the experiments by psychologists, including the Gestalt psychologists, have been irrelevant.

As for the 'non-objective' painters, they scorn to represent domestic objects, animals, persons, Gods, interiors, or landscapes in the old-fashioned way, but they claim that the forms and colors they put on canvas yield a direct experience of 'space'. What can be meant by that overworked term in this connection? Another paradox is the assertion that a still picture can yield an experience of 'motion'. Those terms are surely inappropriate in their 
physico-mathematical meanings, but is there some truth in the claims?

Vision is simplest when it fulfills its function, not when it meets the criterion of one-to-one projective correspondence in geometry. Its function is to help the observer cope with the environment.

\section{WHAT IS A PICTURE?}

The science of language is well established but nothing even approximating a science of depiction exists. What artists, critics, and philosophers of art have to say about pictures has little in common with what photographers, opticists, and geometers have to say about them. They do not seem to be talking about the same topic. No one seems to know what a picture is.

Besides showing pictures to people, I have been trying to formulate a definition of a picture for years, but I have had to change it repeatedly as my optics shifted and my theory of perception developed. Perhaps the abandoned definitions will prove interesting as history. They can be found in four essays [2-5], only the last of which I would stand by.

\section{The picture as an array}

All along I have maintained that a picture is a surface so treated that it makes available a limited optic array of some sort at a point of observation. The difficulty was, an array of what? My first answer was an array of pencils of light rays. My second was an array of visual solid angles, which become nested solid angles after a little thought. My third answer was an array considered as a structure. And the final answer was an arrangement of invariants of structure.

1. An array of pencils of light coming to the pupil of an eye such that each corresponds in brightness (and hue, if any) to its radiating element of the picture surface. This formula was my early attempt to apply classical optics to a picture. Since each pencil could be reduced to a single line from an element of the picture to the nodal point of the eye, I called the array a 'sheaf of rays', as in projective geometry, which was confusing. (See the controversy about this in the Handbook of Perception [6,7].) There are many objections to this definition. For one thing the supposed correspondence of brightness and color between elements of the array and elements of the picture is a great mystery. I was thinking of paintings and photographs that had what I called fidelity to the scene depicted, and the only kind of fidelity I could think of was of elements.

2. An array of nested visual solid angles at the station point determined by steps or contrasts of intensity and spectral compostition of the ambient light. This definition is better, since it emphasizes the relations between genuine parts of an array instead of an abstract sheaf of lines intersecting at the eye each with its point-sensation. The forms on the picture surface are unique, and are included within larger forms. The solid angles coming from a picture to its station point are analogous to the solid angles coming from the faces and facets of a layout to a point of observation.

3. An array considered as a stationary structure. This definition is still better since structure includes gradients, discontinuities, and textures as well as simple contrasts. It begins to be information about an environment, not just stimulation. There are relations between relations, for which there are no names and no mathematical expressions. Gradual transitions in the array can specify shadows and curvatures in the world over and beyond the faces and facets of surfaces.
4. An array of persisting invariants of structure that are nameless and formless. This definition is the most general of all. It assumes that some of the invariants of an array can be separated from its perspective structure not only when the perspective keeps changing, as in life, but also when it is arrested, as in a picture. This says that formless invariants can be detected in a picture that seems to consist entirely of forms. Ordinarily these invariants underlie the transformations and emerge most clearly when the persisting properties separate off from the changing properties, but they can also be distinguished in the limiting case of an unchanging structure.

The four essays on picture perception referred to above culminated in a fifth paper devoted to the concept of formless invariants [8]. Despite the argument that since a still picture presents no transformation it can display no invariants under transformation, I ventured to suggest that it did display invariants, even if weaker than those that emerged from a motion picture.

If it is true that the perception of a detached object is not compounded from a series of discrete forms of that object but depends instead on the invariant features of that family of forms over time, it follows that an arrested member of that unique family will have at least some of those invariants. If object perception depends on invariant detection instead of form perception, then form perception itself must entail some invariant detection.

This says that when the young child sees the family cat at play, the front view, side view, top view, and so on are not seen, and what gets perceived is the invariant cat. The child does not notice the aspects or perspectives of the cat until he is much older; he just sees the cat rolling over. Hence when the child first sees a picture of a cat he is prepared to pick up the invariants, and he pays no attention to the frozen perspective of the picture, drawing, photograph, or cartoon. It is not that he sees an abstract cat, or a conceptual cat, or the common features of the class of cats, as some philosophers would have us believe; what he gets is the information for the persistence of that peculiar, furry, mobile layout of surfaces.

When the young child sees the cat run away he does not notice the small image but sees the far-off cat. Thus, when he sees two adjacent pictures of Felix in the comic book, one large at the bottom of its picture and another small higher up in its picture, he is prepared to perceive the latter as farther off. When he sees the cat half-hidden by the chair he does not perceive a half cat but a partlyhidden cat, and therefore he is prepared to see the same thing in a drawing.

The child never sees a man as a silhouette, or a cutout like a paper-doll, but probably as a sort of head-bodyarms-legs invariant. Consequently, any outline drawing with this invariant is recognized as a man, and the outlines tend to be seen as the occluding edges of a man with interchangeable near and far sides. Even when the outlines give way to line segments, as in so-called stickfigures, the invariant may still be displayed and the man perceived.

The perceiving of the cat-on-the-mat contains invariants that are not explicit, but they can be pictured. The gradient of size and the gradient of density of texture are invariants; the horizon considered as the line where sizes and textures diminish to zero is an invariant. There are many kinds of them.

To summarize, a picture is a surface so treated that it makes available an optic array of formless invariants at a point of observation. The point of observation is fixed, not moving. The optic array is delimited, not ambient, and its visual solid angle seldom exceeds $90^{\circ}$ except for so- 
called 'panoramic' pictures. The array is arrested, in time, except for the case of the motion picture, which will not be considered here. The surface can be treated in many ways so as to make the array available: by painting or drawing or depositing pigment on it so as to modify its reflectance or its transmittance; by engraving or indenting it so as to make shadows and give relief; or by casting light and shade on it so as to produce a temporary picture, in which case we call the surface a screen and the shadow-caster a projector. These fundamental ways of producing an artificial array were discussed in Chapter II of my earlier book on perception [9]. Whatever the artist may do, however, he cannot avoid showing his surface in the midst of other surfaces of an environment. A picture can only be seen in a context of other non-pictorial surfaces.

The enormously complex technologies of picturemaking fall into two different types, the photographic methods, which are only a hundred and fifty years old, and what I call the chirographic methods [10], which have been practiced for at least twenty thousand years. The former involve a camera with accessory equipment for the hand-eye system of a human observer while the latter involve a graphic tool of some sort for the hand-eye system. The invariants made available by these two ways of treating a surface have much in common but are not equivalent, as will be evident in the next section.

Note that the treatment of a surface so as to display invariants excludes the case where the surface is treated so as to modify it as such. It can be ornamented, decorated, embellished; its reflectance can be altered; its texture can be changed, all these without causing it to specify something other than what it is, a surface. No doubt there are intermediate cases between decoration and depiction, especially in architecture, but the extremes are distinct. The painter who is a decorator and the painter who is a depictor are different people and should not be confused. Esthetics, in my opinion, has nothing to do with it. We can distinguish between a surface as an esthetic object and a surface as a display of information. The surface that displays information may also be an esthetic object, but the cases are different. A picture is a surface that always specifies something other than what it is.

\section{The picture as a record}

The above definition is not sufficient. To say that a picture yields an array of optical information clears up a welter of confusion, I think, but it does not say enough. A picture is also a record. It enables the invariants that have been extracted by an observer, at least some of them, to be stored, saved, put away and retrieved, or exchanged. Pictures are liking writing inasmuch as they can be looked at again and again by the same observer and looked at by many observers. They allow the original observer to communicate in a fashion with unborn generations of other observers. Art museums like libraries, are storehouses of knowledge and they permit knowledge to accumulate. Pictures convey knowledge at second hand, and thus are efficient methods of teaching the young. But the knowledge they convey is not explicit. It is not put into words. Most of the formless invariants in the array from a picture could not be put into words anyway. They can be captured by an artist but not described.

What exactly is a picture a record of? I used to think that it was a record of perception, of what the picturemaker was seeing at the time he made the picture at the point of observation he then occupied. It can be a record of perception, to be sure, and a photographic picture is such a record, but the chirographic picture need not be. There are several kinds of non-perceptual experiences that I tried to describe in the last chapter, and the artist can make a record of these just as well as he can of what he perceives. He can record imaginary things, from the probable and possible all the way to the most fantastic of his dreams and hallucinations. He can paint his recollection of something that no longer exists. He can paint fictions. And even when he is perceiving, he is seeing into the past and the future to some extent, so that he captures more than the surfaces projected at the instantaneous present.

Even a photograph records a field of view, a sample of the ambient light, and is thus analogous to looking with the head. It is a record of what the photographer selected for attention. A chirograph is even more selective. Any picture, then, preserves what its maker has noticed and considers worth noticing. Even when he paints a fiction or a fantasy he does it with invariants that have been noticed in the course of learning to perceive.

\section{A THEORY OF DRAWING AND ITS DEVELOPMENT IN THE CHILD}

Let us consider this remarkable business of preserving what one is aware of; let us try to understand it [11-14]. Cro-Magnon man drew pictures of what interested him on the walls of caves, and men of all cultures have been drawing pictures ever since. All of us can draw, even those who never learned to write. Writing was not invented until our ancestors learned to record their words on a surface and that is harder to learn than recording an awareness. Ideographs and syllabaries and alphabets would never have been devised if men had not already been drawing for thousands of years. But what is drawing?

The lore and literature of drawing-masters and schools of art provide no help in answering this question. The manuals on how to draw are thoroughly confusing, for there has never been a coherent theory of the cooperation of the eye and the hand. Courses in mechanical or geometrical drawing using a ruler and compass do not answer the question. Neither do courses in architectural drawing. The courses in so-called graphics that I am familiar with are full of inexcusable contradictions, glossed over for the sake of covering up ignorance. The courses in so-called basic design are equally sloppy. Do we now have a coherent theory of the cooperation of eye and hand? Not yet, but perhaps we can make a beginning.

\section{The fundamental graphic art}

In the child both drawing and writing develop from what I call the fundamental graphic act, the making of traces on a surface that constitute a progressive record of movement [15]. Presumably our primitive ancestors had also been making and observing traces long before the first artist discovered that by means of lines one could delineate something. The first man to make a mammoth appear on the wall of a cave was, I am confident, amazed by what he had done. The chimpanzee can make scribbles and do finger-painting but he cannot draw anything.

The words we have for this fundamental graphic act are ones that describe it badly and belittle it, scribbling, dabbling, doodling, daubing, scratching and so on. But we should study it carefully and not belittle it. Of all the hand-held tools that have been invented, the sort that makes traces on a surface is especially noteworthy, the stylus, brush, pen, pencil, crayon or marker. The movement of the tool over the surface is both felt and seen. The muscle-joint-skin kinesthesis is emphasized by orthodox sensory psychology and the visual kinesthesis is emphasized by my perceptual psychology. But these are transient awarnesses. The seeing of a progressive record of 
the movement of the tool is lasting. There is a track or trail of the movement like the afterimage of a firebrand whirled in the darkness except permanent, a stroke, stripe, or streak, in short a trace. This emphasizes lines and pointed tools but the same principles hold for patches and brush-like tools.

The young child practices the fundamental graphic act in sand, mud, or a plate of food, to the dismay of his parents. When giving a tracing tool, the child does so on approved surfaces as soon as he can hold the tool, beginning at around 16 months of age. The permanent trace is what interests the child. Gibson and Yonas found that one-and-a-half to three-year olds who scribbled zealously with a pencil would stop when a non-tracing pencil that provided everything but the trace was secretly substituted. Moreover three-year old scribblers in a nursery school refused to 'draw a picture in the air' on request, and asked for paper on which they could draw a 'real picture'.

Now consider what the child will begin to notice as he sees the accumulating traces on a surface, and if he sees them frequently. He has no words for what is there; in fact there are no adequate terms for it.

The quality called straight will look different from that called curved, and there are opposite curves.

The trace can begin and end, or it can be continuous.

A continuous trace can change direction with a jerk, a zigzag, although terms like angle and apex will not be learned for years.

A line can be made between existing marks to connect them and marks can be lined up.

A continuous trace can come back to where it began whereupon a peculiar feature emerges that we call closure.

A continuous trace is apt to produce an invariant called intersection. That is, it makes connections.

Traces that do not intersect are very peculiar, and some have the quality of parallel.

It will become evident that a new trace which exactly follows an old one adds nothing to the display, although the term coincide is not yet learned.

It may be noticed that a trace on one sheet of paper can be fitted over a trace on another sheet, in the same way that a child's block can be fitted into an aperture (the template, or so-called formboard). This is preparation for the axiom of congruence in Euclidean geometry.

All of these features in the scribbles of childhood are invariants. While they are getting noticed in the child's own trace-making they are surely being noticed in the pictures that are shown to him in the nursery, and eventually some of the natural invariants that appeared in the ambient array from the outset will begin to be identified with the graphic invariants.

\section{Replicating or copying}

Copying is fundamentally the act of making traces on a surface that coincide with the traces on another surface, either one overlaid on it or one that could be overlaid on it. The child can 'trace over' an existing trace, or he can 'trace' an existing pattern on a transparent or semitransparent overlay so as to replicate it. He can thus perceive the congruence of the two patterns. He learns how to match traces and to see the match, or the mismatch, of separated traces. Eventually he will learn other methods of printing and template matching but the graphic method, I suggest, comes first.

To copy by comparison is harder than to copy by coincidence tracing. The ability to copy 'freehand' a diamond-shaped form is not achieved by the average child until age seven, according to the Binet Test norms. What we call free-hand trace-making refers partly to the fact that the movement of the tool is not constrained by a ruler, compass, scale, or other drawing instrument. But it is controlled by something and it is, I suggest, invariants of the sort listed.

A special case of coincidence-tracing is the method for making a perspective drawing of a scene on a sheet of glass, the method of artificial perspective discovered by the painters of the Renaissance. It was recommended by Leonardo da Vinci. You set up the glass as if it were a window. Then, keeping one eye exactly fixed in front of the window, you draw lines on the surface to coincide with the projections of the occluding edges of the layout, the edges and corners of the layout (the dihedrals) and the fissures, sticks, fibers, and pigment-borders. You cannot trace the penumbras of shadows or the shading of curved surfaces, however, and the method is not as easy as it is made to sound. Actually it is not a practicable method but a sort of demonstration of how to visualize the surface of the canvas as if it were a transparent picture plane. The implication is that something like free-hand copying is possible for a scene as well as for another drawing. But this, I believe, is false.

\section{Drawing proper}

By gradual stages the human child begins to draw in the full meaning of the term, to draw a man, a house, a flower, or the sun in the sky. He is still making lines on a surface that record the movements of the tool in his hand, but he is now also recording an awareness in terms of the invariants he has picked up. He delineates for himself and others something he has apprehended or experienced. The traces he leaves on the paper are not just lines, or the outlines of forms, but the distinguishing features of the environment. While drawing, he may be looking at something real, or thinking about something real, or thinking about something wholly imaginary; in any case the invariants of his visual system are resonating. The same is true of the artist as of the child. The invariants are not abstractions or concepts. They are not knowledge; they are simply invariants.

Let us contrast this theory of drawing with the traditional theory. The latter assumes that drawing is one of three sorts: drawing from 'life', from 'memory', or from 'imagination'. Drawing is always copying. The copying of a perceptual image is drawing from life. The copying of a stored image is drawing from memory. The copying of an image constructed from other memory images is drawing from imagination. This theory of drawing is consistent with the mentalistic doctrine which assumes an optical image on the retina, a physiological image in the receptors, a transmitted image in the nerve, a cerebral image in the brain, and finally a mental image in the mind that is subject to all sorts of creative transformations.

How is the copying of an image supposed to occur? An ancient metaphor is often appealed to, the projection of an image outward from the eye. Many persons ignorant of vision find this easy to accept. (The notion is lent a false plausibility by the fact that the after sensation caused by overstimulating the retinal receptors with a strong light is called an afterimage, and is visible on any surface looked at as long as the eye is fixed. If a physiological afterimage impressed on the retina can thus be thrown outward, why not a mental afterimage imposed on the brain? So the reasoning goes.) Drawing from life would consist of looking at the model and getting an image, looking at the drawing pad, and then just tracing around the outline of the projected image. Drawing from memory or imagination would differ only in that the artist has to 'consult' his memory and 'summon' an image. If you cannot trace around the projected mental image at least you can copy it 
free-hand. Perhaps drawing is not exactly like this, they say, but something like this. Otherwise what could it be? The projecting of a mental image outward upon an existing drawing is even supposed to explain one's perception of the drawing, as Gombrich for example maintains [16].

I insist that what the draftsman, beginner or expert, actually does is not to replicate, to print, or to copy in any sense of the term, but to mark the surface in such a way as to display invariants and record an awareness. Drawing is never copying. It is impossible to copy a piece of the environment. What can be copied is only another drawing. We have been misled for too long by the fallacy that a picture is similar to what it depicts, a likeness, or an imitation of it. A picture supplies some of the information for what it depicts, but that does not imply being in projective correspondence with it.

\section{The muddle of representation}

If this new theory is correct, the term representation is misleading. There is no such thing as a literal representation of an earlier optic array. The scene cannot be re-established; the array cannot be reconstituted. Some of its invariants can be preserved but that is all. Even a photograph, a color photograph at its technological best, cannot preserve all the information at a point of observation in a natural environment, for that information is unlimited. As for re-presenting the stimulation in the sense of re-imposing an old pattern of light energies on the retina, that is quite impossible. The full range of energies and wave-lengths in light cannot be preserved on film. It can capture some of the ratios, the contrasts or relations in the light, but not the sensations of brightness and color.

The efforts made by philosophers and psychologists to clarify what is meant by a representation have failed, it seems to me, because the concept is wrong. A picture is not an imitation of past seeing. It is not a substitute for going back and looking again. What it records, registers, or consolidates is information, not sense-data.

\section{WHAT ABOUT THE ILLUSION OF REALITY?}

A picture is not like perceiving. Nevertheless a picture is somehow more like perceiving an object, place, or person than is a verbal description of it. The illusion of reality is said to be possible. Painting can reach a degree of perfection, we are told, such that a viewer cannot tell whether what he sees is a canvas treated with pigments or the real surfaces that the painter saw, viewed as if through a window. In his monumental study of pictorial representation Gombrich [17] repeats the story of the Greek painter who had imitated grapes so perfectly that the birds came to peck at them, and the story of his rival who bested him by painting a curtain so deceptively that the painter himself tried to lift it from the panel. The tradition of 'fooling the eye' is very ancient. The assumption that a false perception of real surfaces can be induced in the art gallery or the psychological laboratory is widely believed. If the artificial array is the same as the natural array, it will yield the same perception. There will arise an illusion of reality without a genuine reality. The eye is easily deceived, and our faith in the reality of what we see is therefore precarious. For two millenia we have been told so.

The purveyors of this doctrine disregard certain facts. The deception is possible only for a single eye at a fixed point of observation with a constricted field of view, that is, for 'peephole' vision. This is not genuine vision, not as conceived in this book. Only the eye considered as a fixed camera can be deceived. The actual binocular visual system cannot. A viewer can always tell whether he is looking at a picture or a real scene through a window. I do not believe the stories about birds and painters being fooled, any more than I believe that Pygmalion really fell in love with his statue. The illusion of reality is a myth. The same automatic tests for reality that distinguish between a perception and a mental image will also distinguish between a perception and a physical image. We go on believing the myth only because it fits with what the authorities tell us about perception, with retinal image optics.

A picture, photographic or chirographic, is always a treated surface, and it is always seen in a context of other non-pictorial surfaces. Along with the invariants for the depicted layout of surfaces there are invariants for the surface as such. It is a plaster wall, or a sheet of canvas, a panel, a screen, or a piece of paper. The glass, texture, edges, or frame of the picture surface are given in the array, and they are perceived. The information displayed is dual. It is both a scene and a surface, and the scene is paradoxically behind the surface. This duality of the information is the reason why the observer is never quite sure how to answer the question, 'What do you see?'. For he can perfectly well answer 'a wall' or 'a piece of paper'. It is this duality in the optic array from a picture that makes the drawing a bad way to begin the study of perception.

I have in my time, like many perceptionists, arranged for a display of information to be seen through a peephole, that is, for viewing it through an aperture close to the eye. This is supposed to minimize the information for the surface as such and enhance the illusion of reality. Far from being a simple expedient, however, I find that it complicates the act of perception. Keeping the observer from making tests for reality does not increase the impression of reality.

No painter and no photographer should ever strive to give the viewer the feeling that he is looking at a real place, object, person, or event. There is no need to do so. In any case, the effort is bound to be a failure.

\section{Experiments on the duality of picture perception}

A picture is both a surface in its own right and a display of information about something else. The viewer cannot help but see both, yet this is a paradox, for the two kinds of awareness are discrepant. We distinguish between the surface of the picture and the surfaces in the picture. In the case of paintings like those of the impressionists we can see the difference between the illumination of the picture and the illumination in the picture. The two sets of surfaces are not comparable, and the two kinds of illumination are not commensurable.

I once took a good sharp photograph of a lawn with trees and a paved walk and had it enlarged about 20 times so that it could be mounted on a six-foot panel. The observer stood at a point where the visual angle of the picture at his eye was the same as the visual angle of the array admitted to the camera. He was told to estimate distances in terms of the number of paces needed. To the question, 'How far away from you is the elm tree?' he would visualize himself walking up to it and reply 'Thirty paces'. But to the question, 'How far away from you is the picture?' he would pause and reply 'Oh, that's four paces'. For the latter estimate he had to shift the operation of his visual system so as to pick up quite different invariants. The lawn in the picture was not connected with the floor of the room. 
Consider next the kind of picture that stands at a far extreme from the photomural above. Psychologists have long been showing ink blots to their subjects and asking what they saw. A set of such random blobs on cards devised by Rohrschach has now been standardized and is in use by clinical psychologists. Faced with a card, a sensible patient might very well say simply that he saw a blot, but he seldom does. He attends to the nameless squiggles, contours, textures, and colors and says 'a bleeding heart' or 'a pair of dancing bears', allowing the psychologist to diagnose his fantasy life. I have argued that a Rohrschach blot is a picture of sorts containing information not only for bleeding hearts and dancing bears but dozens of other events [18]. It is different from a regular picture in that the invariants are all mixed up together and are mutually discrepant instead of being mutually consistent or redundant. It is rather like a mass of scribbles for a child in this respect.

The old mentalistic explanation of perceiving objects in clouds and inkblots, incidentally, is projection, the projecting outward of fantasy images from the unconscious mind as if by a mental magic lantern. Hence the Rohrschach is called a 'projective' test. A somewhat more respectable explanation derived from Gestalt theory is a supposed process that mentally structures an 'unstructured stimulus', the blot, in accordance with the imagination.

What are we to call the tree in the photograph, or the bleeding heart in the inkblot? It is not an object in my terminology. I am tempted to call it a virtual object. It is not perceived and yet it is perceived. The duality of the information in the array is what causes the dual experience. We need to understand the apprehension of virtual objects and, of course, virtual places, events, and persons. We can only do so in connection with the perceiving of the real surfaces of the environment, including the picture surfaces. Note that our distinction between virtual and real will have to be independent of the distinction in classical optics between virtual and real images, which is swamped in epistemological confusion.

I conclude that a picture always requires two kinds of apprehension that go on at the same time, one direct and the other indirect. There is a direct perceiving of the picture surface along with an indirect awareness-an indirect perceiving, knowing, or imagining of virtual surfaces as the case may be.

\section{THE POWER OF PERSPECTIVE IN PAINTING}

If it is not true that a picture in perspective represents reality and a picture not in perspective fails to represent reality, what is true? My answer is that if a picture displays the perspective of a scene it puts the viewer into the scene but that is all. It does not enhance the reality of the scene. The seeing of oneself is not negligible but it is not the sole aim of depiction. The advocates of perspective representation are mistaken, but those who reject perspective as a mere convention are also mistaken. There is complete confusion on all sides. The terms in which that debate has proceeded are thoroughly misleading.

The dogma that linear perspective adds depth to a picture along with the other kinds of perspective that are 'cues' for depth is a source of endless confusion. The term perspective is generally misunderstood. The theory of projection on a transparent picture plane to a stationpoint is a Renaissance discovery that is properly called artificial perspective. The theory of the ambient optic array from an environment to a point of observation should be called natural perspective and is not all the same thing. Artificial perspective leads to a set of prescriptions for producing virtual streets, buildings, and interiors seen from a fixed position and a corollary requiring that the painting be viewed with one eye at a unique station point. Natural perspective leads to ecological optics and the concept of the invariant structure in a changing optic array. On the one hand, painters are inclined to reject the prescriptions of artificial perspective but are then tempted to disbelieve in any kind of perspective. On the other hand, scientists who are impressed with classical optics and the elegance of projective geometry are tempted to disbelieve in the efforts of modern painters. Each side is talking past the other.

What they need to understand in order to find a common ground, I think, is how it is possible for an observer to see something from no point of observation as well as from a given point of obseivation, that is, from a path of observation as well as a position. What modern painters are trying to do, if they only knew it, is paint invariants, It is not abstractions, not concepts, not space, not motion, but invariants that should interest them.

The separation of invariant structure from perspective structure is the heart of the problem. The invariants display a world with nobody in it and the perspective displays where the observer is in it. One can depict without a fixed point of observation, just as one can visualize without a point of observation, although it is not easy to understand how. But depiction with a point of observation is the more natural sort, and the photographic picture is necessarily of this sort.

The picture that locates the observer in a virtual environment can arouse a powerful experience. There are metaphors to describe it: one is taken out of oneself, one is transported, one is set down in a far place. It may be a distant part of the real environment or another world. Travel pictures take one to where the traveller has been. Battle pictures take one into the heart of the melee. Historical pictures take one to the forum of ancient Rome. Religious pictures take one straight to Heaven, or Hell. The viewer sees himself in the environment for it extends out beyond the frame of the picture.

It is not an illusion of reality that is induced in these pictures, but an awareness of being in the world. This is no illusion. It is a legitimate goal of depiction, if not the only one.

\section{IS DEPICTION A FORM OF DESCRIPTION?}

It is troublesome for a painter to follow the prescriptions of artificial perspective as any serious work on the subject clearly shows [cf., for example, 19]. Even when the prescriptions are followed, it is impossible to enforce the rule for the beholder, for no viewer can be expected to maintain one eye at the proper station point in the air in front of the picture even if the art gallery provided a biteboard or head-rest to specify the viewpoint for each painting hung. But that is the only way to prevent distortions of the virtual layout, as students of perspective have long known and as the book by Pirenne [20] has fully explained. The distortions themselves are not all that serious. Perspective was not worth the trouble, painters thought. The photographer could make an exact perspective picture automatically so why bother to master all that geometry? Let him have his perspective! It was complicated and controversial business in any case. Visual scientists with all their theorizing know little about the actual art of painting. A fine art should not be subject to rules and regulations. This is the attitude of many modern painters and most schools of art. 
The theory that artificial perspective is no more than a convention of Western art is a way of justifying this attitude. Panofsky [21] asserted that perspective is 'symbolic'. Kepes [22] has written about the 'language' of vision. Arnheim [23] believes that we will learn to see what is represented by abstract painters even if we now cannot, and Goodman in Languages of Art [24] assumes that depiction is fundamentally description, that we learn to read a picture as we learn a language and that linear perspective could just as well be reversed from the way we have become accustomed to interpret it.

Now it is one thing to argue that the use of perspective is not necessary for a painting but it is quite another to say that perspective is a language. That says both the perspective and the invariants of a picture must be analogous to words and that, just as we can learn a new vocabulary, so we can learn a new mode of perception. If a language of words can be invented like Esperanto, why not a language of art? But the essence of a picture is just that its information is not explicit. The invariants cannot be put into words or symbols. The depiction captures an awareness without describing it. The record has not been forced into predications and propositions. There is no way of describing the awareness of being in the environment at a certain place. Novelists attempt it, of course, but they cannot put you in the picture in anything like the way the painter can.

\section{THE CONSCIOUSNESS OF THE VISUAL FIELD}

The doctrine of flat visual sensations, together with the theories of sensation-based perception, of the cues for depth, and of how the cues get interpreted, developed in close connection with the rise of perspective painting from the Renaissance to the 19th Century. A picture was obviously a patchwork of pigments on a surface. By analogy, the picture in the eye was a patchwork of colored light on the retinal surface. Hence the deliverance of the eye to the mind was a corresponding patchwork of visual sensations, This was supposed to be what the infant saw at birth, and what a man born blind but given sight by the removal of a cataract saw at first when the bandage was removed [25]. It was the innate basis of visual perception, the product of untutored vision, unprejudiced by learning. The duty of a painter, said Ruskin, was to recover the innocent eye of his infancy in depicting nature [26]. All psychologists accepted the doctrine of twodimensional sensations; they disagreed only in that some believed the cues for depth to be wholly learned whereas others supposed that concepts of space were innate.

It has been generally believed that even an adult can become conscious of his visual sensations if he tries. You have to take an introspective attitude, or analyze your experience into its elements, or pay attention to the data of your perception, or stare at something persistently until the meaning fades away. I once believed it myself. I suggested that the 'visual field' could be attended to, as distinguished from the 'visual world', and that it was almost a flat patchwork of colors, like a painting on a plane surface facing the eye [27]. The awareness of depth in the scene could not be wholly eliminated, I thought, but it could be reduced. The similarity to a painting could be enhanced by not rotating the head and not displacing it, by closing one eye, and by avoiding any scene with motion. I recognized even then that the normal field of view of an ocular orbit is continually changing and that an arrested pattern is exceptional.

My comparison of the visual field to a perspective painting, although guarded, now seems to me a serious mistake. No one ever saw the world as a flat patchwork of colors, no infant, no cataract patient, and not even Bishop Berkeley or Baron von Helmholtz, who believed firmly that the cues for depth were learned. The notion of a patchwork of colors comes from the art of painting, not from any unbiased description of visual experience. What one becomes aware of by holding still, closing one eye, and observing a frozen scene is not visual sensations but only the surfaces of the world that can be seen now from here. They are not flat or depthless but simply unhidden. One's attention is called to the fact of occlusion, not to the psuedo fact of the third dimension. One notices the surfaces that face me, and what I face, and thus where I am. The attitude might be called introspective or subjective but it is actually a reciprocal two-way attitude, not a looking inward.

\section{What is it to see in perspective? Patchword perspective vs edge perspective}

One can learn to see an object in perspective, or a whole vista, but that does not imply learning to see it as if it were a picture. One does not flatten out the object or the scene as if painting it on a picture-plane; all one does is separate the hidden from the un-hidden surfaces and observe the occluding edges. The natural perspective of visual solid angles is what counts here, not the artificial perspective of pigment-patches.

Drawing in perspective does depend on seeing in perspective, it is true, but this only means that drawing requires the learner to notice the edges of the layout confronting him, especially the occluding edges. He must also notice other invariants, of course, but the edges are the fundamental basis for his picture. What we loosely call an 'outline' in a picture refers to the outer edges of the face of an object. It is the surfaces that need to be specified first in a picture; the colors, textures, shadows, and illumination can be rendered later. I am saying that edge perspective is a fact whereas patchwork perspective is a myth. One can learn to see the former but not the latter.

The young child learning to draw has long interested both psychologists and artists. When he first draws a man, or a truck, or a table, I suggest, he depicts the invariants that he has learned to notice. He does not draw in patchwork perspective, for he never had the experience of a patchwork. He may not yet draw in edge-perspective because he has not noticed it. Hence he may draw a table with a rectangular top and four legs at the corners because those are the invariant features of the table he has noticed. This is a better explanation than saying he draws what he knows about the table, his concept, instead of what he sees of the table, his sensation. The fatal flaw of the latter explanation is that it ought to be the other way around. The child should begin by drawing sensations and progress to drawing concepts.

\section{THE PRINCIPLES OF LINE DRAWING}

To the extent that the natural optic array is composed of visual solid angles, and only to that extent, the information in the array can be captured by a line drawing. The envelopes of the solid angles, being discontinuous, must correspond to discontinuities in the environment instead of gradual transitions. More precisely, a line drawing can specify the following invariants of surface layout: a corner (the apex of a concave dihedral), an edge (the apex of a convex dihedral), an occluding edge (either apical or curved), a wire (fiber), a fissure (crack in a surface), and a skyline (horizon between earth and sky). A line drawing cannot 
specify the following invariants: the shading on a curved surface, the penumbra of a cast shadow, the texture of a surface, or the reflectance (color) of a surface, although it can specify an abrupt discontinuity of shading, of texture, and of color.

The lines of a drawing must connect with one another and divide the pictures into superordinate and subordinate areas in a lawful way. There have to be visual solid angles at the station point of the picture analogous to visual solid angles at the point of observation of a natural optic array, those coming from the faces of surfaces, the openings between surfaces, and the patches of sky. The lines that separate areas on the picture plane should therefore not be called outlines for this term implies detached objects in empty space and the fallacy that figure-on-ground is the prototype of perception. The term refers mainly to the occluding edge of a detached object but not that of an aperture. A line in a line drawing can occlude either inward or outward depending on its connection with other lines. And a convex or concave dihedral, the junction of two planar surfaces, is given by a line, but this is not an 'outline'. The term outline drawing should be confined to the unusual and misleading case of a line with closure, one that returns upon itself, a form, and this kind of display contains only the weakest sort of information about anything, as I pointed out at the beginning. It does not even specify the solid shape of a detached object.

The information in a line drawing is evidently carried by the connections of the lines not by lines as such. To put it another way, the invariants are found in the ways that the areas are nested, not in the forms of these areas. These ways are difficult to describe in words. The connections, junctions, and intersections of lines remain invariant under a changing perspective of the surfaces.

If a line in a drawing is connected up at one end in one way and at the other end in an incompatible way, it may specify a discrepancy in the layout of surfaces. This is the basis, I think, of the depictions of 'impossible objects' that have recently gained popularity.

These anomalies of depiction can be combined in very elaborate ways as the drawings of the Dutch graphic artist Escher have demonstrated. Far from proving that the beholder creates the world he perceives in a picture, however, they suggest the existence of laws of optical information that are general and exact.

One thing at least should be clear: the 'lines' of line drawings and the 'lines' of geometry are entirely different. The depicting of surfaces should not be confused with the ghosts of abstract geometry. We are taught in geometry that a line is derived from points, a plane from lines, and a space from planes. We learn the three axes of Descarte's coordinate geometry and the concept of space as a sort of box-like container of points and lines that combine to make planes and solids, conceived for the benefit of abstract physics. Hence the modern artist is constrained to assume what Paul Klee asserted, namely that the graphic elements available to the painter are 'points, lines, planes, and volumes'. When the artist works to capture invariants, all that he knows to say about what he is doing is that he depicts 'space'. But this is misleading.

Kennedy [28] has described many of the characteristics of line drawings in much the same spirit that has been adopted in this chapter. But his conception of optical information is imprecise, it seems to me, since it is not based on ecological optics.
The capturing of optical invariants by line drawings is a fascinating exercise. It has seemed to be both familiar and mysterious. It is not, however, fundamental. Much of the information in a natural optic array is lost in a drawing inasmuch as the array cannot be reduced to nested solid angles. The invariants under changing illumination and those under the changing direction of the prevailing illumination are lost. So are the invariant relations that specify the textures and colors of surface. Some of these are captured by painters who use a variety of tools other than the pen or pencil. But mostly what is lost in a picture, drawing, painting, or photograph is the information that can only be extracted from the changing perspective structure of the ambient optic array of a moving observer.

\section{REFERENCES}

1. J. J. Gibson, The Reproduction of Visually Perceived Forms, J. Exper. Psychol. 12, 1 (1929).

2. J. J. Gibson, A Theory of Pictorial Perception, Audiovisual Communic. Rev. 1, 3 (1954).

3. J. J. Gibson, Pictures, Perspective, and Perception, Daedalus 89, 216 (1960)

4. J. J. Gibson, The Senses Considered as Perceptual Systems (Boston: Houghton-Mifflin, 1966) Ch. 11.

5. J. J. Gibson, The Information Available in Pictures, Leonardo 4, 27 (1971).

6. R. M. Boynton, The Visual System: Environmental Information, in E. C. Cartarette and M. P. Friedman, Handbook of Perception, Vol. 1 (1974) Ch. 14.

7. J. J. Gibson, A Note on Ecological Optics, in E. C. Cartarette and M. P. Friedman, Handbook of Perception, Vol. 1 (1974) Ch. 15.

8. J. J. Gibson, On the Concept of Formless Invariants in Visual Perception, Leonardo 6, 43 (1973).

9. cf. Ref. 4, Ch. 11

10. cf. Ref. 2, p. 21

11. J. J. Gibson, Motion Picture Testing and Research, Report No. 7, AAF Aviation Psychology Research Reports, U.S. Government Printing Office, (1947) Ch. 8.

12 cf. Ref. 2.

13. J. M. Kennedy, A Psychology of Picture Perception (San Francisco: Jossey-Bass, 1974)

14. R. Arnheim, Art and Visual Perception (Berkeley: Univ. of Calif. Press, 1954)

15. cf. Ref. 4, Ch. 11.

16. E. H. Gombrich, Art and Illusion (Princeton: Princeton Univ. Press, 1960)

17. cf. Ref. 16, p. 206

18. J. J. Gibson, The Non-projective Aspects of the Rohrschach Experiment: The Rohrschach Blots Considered as Pictures, J. Soc. Psychol. 44, 203 (1956).

19. W. R. Ware, Modern Perspective (New York: Macmillan, 1900).

20. M. H. Pirenne, Optics, Painting, and Photography (Cambridge: Cambridge Univ. Press, 1970).

21. E. Panofsky, Die Perspective als Symbolische Form. (Vortrage der Bibliothek Warburg, 1924-1925).

22. G. Kepes, The Language of Vision (Chicago: Paul Theobald, 1944).

23. cf. Ref. 14

24. N. Goodman, Languages of Art: An Approach to a Theory of Symbols (New York: Bobbs-Merrill, 1968).

25. M. von Senden, Space and Sight. Tr. by P. Heath (London: Methuen, 1960).

26. cf. Ref. 16, p. 296.

27. J. J. Gibson, The Perception of the Visual World (Boston: Houghton-Mifflin, 1950) Ch. 3.

28. cf. Ref. 13. 
OTHER TEXTS IN LEONARDO BY J. J. GIBSON

1. Letters, Leonardo 2, 329 (1969).

2. On the Relation between Hallucination and Perception, Leonardo 3, 425 (1970).

3. Letters, Leonardo 4, 197, 308 and 405 (1971).

4. On the Concept of 'Formless Invariants' in Visual Perception, Leonardo 6, 43 (1973).
5. Letters, Leonardo 6, 284 (1973).

6. Visulizing Conceived as Visual Apprehending without Any Particular Point of Observation, Leonardo 7, 41 (1974).

7. Letters, Leonardo 7, 383 (1974).

8. Pickford and the Failure of Experimental Esthetics, Leonardo 8, 319 (1975).

9. Letters, Leonardo 9, 87, 260 and 348 (1976). 